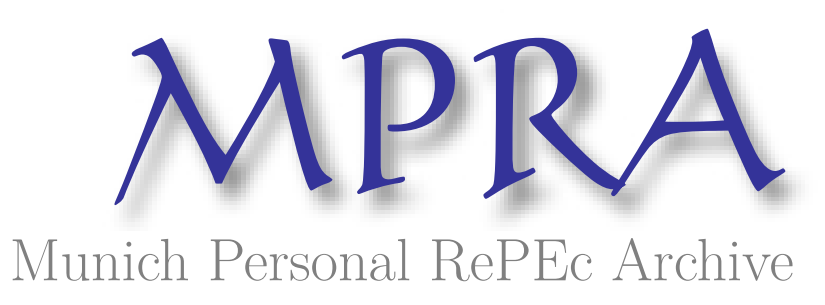

\title{
Evaluating Public Policy Formation and Support Mechanisms for Technological Innovation
}

Ramsey, Elaine and Bond, Derek

July 2006

Online at https://mpra.ub.uni-muenchen.de/253/

MPRA Paper No. 253, posted 09 Oct 2006 UTC 


\title{
EVALUATING PUBLIC POLICY FORMATION AND SUPPORT MECHANISMS FOR TECHNOLOGICAL INNOVATION
}

\author{
Elaine Ramsey \\ Lecturer in E-Marketing \\ University of Ulster at Coleraine, UK, BT52 1SA \\ $+44(0) 2870323335$ \\ $+44(0) 2870324910$ \\ e.ramsey@ulster.ac.uk \\ Derek Bond \\ Senior Lecturer \\ University of Ulster at Coleraine, UK, BT52 1SA \\ $+44(0) 2870324350$ \\ $+44(0) 2870324910$ \\ d.bond@ulster.ac.uk
}

\begin{abstract}
Policy evaluation is a complex task. Most approaches now adopt a mixed method approach combining both quantitative and qualitative techniques. A shortcoming of the standard approaches is that they fail to measure or investigate deeper perceptions of the policy. In this paper the usefulness of projective techniques as a tool for policy evaluation is investigated. Projective techniques are widely used in psychology and consumer studies but their usefulness in policy evaluation has still to be assessed. A simple evaluation is done in this paper by reporting on a study of owner-managers of tradeable-services small and medium size enterprises attitudes to Government e-business policy. The survey included firms from Northern Ireland, Republic of Ireland and New Zealand. Traditional quantitative and qualitative survey techniques were used, however these failed to produce conclusive evidence. To overcome this limitation two projective techniques- word association and completion tests were employed as an additional evaluation method. The paper illustrates how the results of projective techniques can be analysed using both context and matrix analysis. Given that the area of e-business is dynamic and fast changing and that SMEs are extremely heterogeneous, it is argued that the application of projective techniques to assess their attitudes and perceptions of government policy is a good test of the usefulness of the method. The results of the projective techniques lead to more insight into the perceptions and attitudes of the owner-managers and provide interesting individual perspectives into the issues. Problems with the method, such as costs, the level of skill needed to apply the technique and generalization are highlighted. The overall conclusions are that projective techniques could provide an interesting additional tool for policy evaluation and that further assessment of its usefulness is needed.
\end{abstract}

\section{KEYWORDS}

Policy evaluation; Projective techniques: E-business; SMEs.

\section{INTRODUCTION}

Normally public policy evaluation consists of attempting to find indicators of either the impact or the tangible deliverables and outputs of an initiative. Such an approach is only applicable when it is possible to find relevant, practical, up-to-date and reliable metrics. Monitoring and evaluating the impact of government policy on the growth in information and communication technologies (ICT) has provided both policy makers and statisticians with many challenges that have yet to be completely resolved (see Nahuis and van der Wiel, 2005 and Bayoumi and Haacker, 2002 for typical discussion of problems facing policy makers and Lowenthal, 1999 for many of the issues facing official statisticians). Standard quantitative approaches to 
measuring the impact of ICT rely on the availability of statistics that adequately describe what is a fast growing and changing field. An example of the challenges faced is the fact that few official measures of the use of ICT yet include any indicators on the use of voice over internet protocol. In an attempt to address these rigidities most evaluation techniques adopt a mixed methods approach combining both quantitative indicators with qualitative measures derived from in-depth interviews. The argument is that policy evaluation is concerned with perceptions and attitudes as well as just outcomes. However, in-depth interviews often encourage politically correct responses and fail to uncover feelings, beliefs, attitudes and motivations which many interviewees find difficult to articulate (Webb, 1992). In both psychology and consumer research projective techniques are used to uncover such issues. The purpose of this paper is to explore the usefulness of the qualitative approach of projective techniques in the evaluation of public policy relative to the development of ICT. In particular, it addresses the issue of whether projective techniques can measure the perceptions that target groups have to public policies. If the perceptions are negative it is unlikely that the policies will have the desired impact.

The assessment of the usefulness of projective techniques is based on a study of how small and medium enterprises (SMEs) in the tradeable services sector perceive public policy aimed at encouraging e-business. To help understand whether the findings can be generalised the paper considers perceptions in Northern Ireland, Republic of Ireland and New Zealand.

The structure of the paper is as follows. In the next section the background to various strands of the paper are introduced. Firstly the issue of policy evaluation of ICT programmes is discussed and the ideas behind projective techniques introduced. The section finishes with a discussion of the background to the study of the attitudes of SME owner-managers in the tradeable service sector. The methodology adopted in the three country study is then outlined. This is followed by a summary of the results obtained by the various techniques. The paper then attempts to evaluate whether the project techniques are a useful tool for policy evaluation. The paper concludes by suggesting future directions in policy evaluation research in the area of ebusiness and SMEs.

\section{BACKGROUND}

The role of e-business as a major driver of economic and social development within the European Union was recognised by the Lisbon Accord signed in 2000. In 2002 the $e$ Europe 2005 initiative was launched to contribute to the Lisbon Strategy for growth by creating a dynamic environment for e-business and modern online public services. As part of its mid-way review of the implementation of the Lisbon accord the European Commission in 2005 set out a new strategic framework for the Information Society: $2010-a$ European Information Society for Growth and Employment building on eEurope 2005.

A central issue of the $e$ Europe initiative has been the ability to monitor and evaluate the effectiveness of the programmes. Two main groups of evaluation studies have emerged. The first are benchmarking studies of various industries and the second in-depth case-study evaluations of the impact of regional and national ebusiness policies. Both groups used a mixed research methodology similar to that advocated by the OECD (c.f. Storey, 2002). Quantitative measures were derived from indicators derived from the Household and Enterprise surveys carried out by the National Statistical Organisations (NSOs) and coordinated by Eurostat, and these were combined with qualitative measures designed and implemented by the evaluators. In the case of the benchmarking exercises the qualitative measures were derived from the Information Society Benchmarking Report (2005). For the case studies evaluators used face to face interviews with key players. In all reports the need for improvements in the evaluation techniques was highlighted as a conclusion (for example EU, 2005a).

A major reason for the adoption of a mixed methodology has been the suggestion that the quantitative methodologies fail to provide anything other than a naïve understanding of what motivates companies to adopt and assimilate ICT to facilitate e-business activities. It would appear that a quantitative approach can, at best, only accommodate a limited understanding of the contextual issues and circumstances which may affect firms (c.f. Bennett and Robson, 1998; Storey, 1994; Kai-Uwe Brock, 2000; Fallon and Moran, 2000). In addition using NSO data excludes, because of the need for the consistency in the sampling frames used in the quantitative surveys, firms who employ less than 10 employees, the so-called micro-enterprises. It is 
these micro-enterprises who seem to have some of the lowest levels of adoption and use of e-business and the internet, (ISI, 1999; Martin and Matlay, 2001).

The qualitative analysis used in these studies also raises methodological issues. A major problem is that simply to 'ask the questions' in an appropriate open-ended method is generally insufficient (Hoskin, 2002). In the seminal works by Edwards (1954) and March and Simon (1958) the concept of 'bounded rationality' was introduced. The principal rationale being that if researchers want to understand 'real' decision behaviour, they have to focus on perceptual psychological and cognitive factors that cause decision-makers to make imperfect decisions. That is how they (decision-makers) interpret new information and direct their behaviour towards the attainment of organisational goals. One possible instrument to achieve such an understanding is projective techniques. In this paper the use of these techniques as a method of evaluation of policies is considered.

To many people projective techniques are synonymous with the Rorschach Inkblot Test. Underlying the techniques is the assumption that unconscious desires and feelings can be inferred by presenting a subject with an ambiguous situation in which he or she has to use the "ego defense" mechanism of projection. The subject is free to interpret and respond to the ambiguous stimuli (material that can be variously interpreted) from his or her own particular frame of reference (Churchill, 1991; Kassarjian, 1974; Loudon and Della Bitta, 1993; Solomon, 1994). As there is no right or wrong answer, it is hoped that the subjects will project their own unconscious feelings in their answers (Solomon, 1994:25).

The techniques were initially developed in clinical psychology where they were used for personality assessment and psychoanalytic treatment (Bellak, 1992; Graham \& Lilly, 1984; Kassarjian, 1974). The techniques were adapted for use in consumer and marketing research (Berkman \& Gilson, 1986; Loudon \& Della Bitta, 1993 and Kassarjian, 1974). The techniques may be classified as a structured-indirect way of investigating the whys of situations (Webb, 1992). They are not used to measure (that is more the territory of other techniques such as surveys), but to uncover feelings, beliefs, attitudes and motivations which many consumers find difficult to articulate (Webb, 1992). Projective techniques help the researcher enter the private worlds of subjects to uncover their inner perspectives in a way they feel comfortable with (Gordon \& Langmaid, 1988; Loudon and Della Bitta, 1993).

The stimuli range from structured (clear and definite) at one extreme, to very ambiguous (unstructured) at the other extreme. It is assumed that the more unstructured and ambiguous a stimulus, the more the subjects will project their emotions, motives, attitudes and values. The structure of a stimulus determines the degree of choice available to the subject. A highly structured stimulus, for example a questionnaire that requires the subjects to read a list of statements and answer "true" or "false" to each, leaves very little choice. The subject has an unambiguous choice among clear alternatives and the stimuli will probably be interpreted similarly by almost everyone who reads them (Graham and Lilly, 1984). Ambiguous stimuli (with little structure), for example Rorschach inkblots, present a wide range of alternative choices and the subjects may choose their own interpretations. Semi-ambiguous pictures and sentence completion techniques represent an intermediate position on the stimulus continuum (Wagner, 1995; Graham and Lilly, 1984).

It is generally accepted that in consumer and marketing research applications, projective techniques should constitute relatively ambiguous stimuli to permit the subjects to interpret the stimuli in terms of their own perceptions and in their own words. The nature of the stimuli should however offer enough direction to evoke some association with the concept of interest (Churchill, 1991; and Gordon and Langmaid, 1988).

The question addressed in this paper is whether these techniques provide an alternative method of obtaining qualitative indicators for policy evaluation. This is done by considering the use of these techniques in a study conducted between 2001 and 2004 with the overall aim of investigating e-business developments among tradeable service sector SMEs in Northern Ireland, Republic of Ireland and New Zealand. The study had several objectives. This paper concentrates on the findings of the specific research aim that investigates owner-managers' perceptions of government support for e-business.

The study concentrated on the tradeable services sector because of its increasingly central role in economic development. Most advanced economies are becoming dominated by their continuingly growing services sector (c.f. Zeithaml and Bitner 1996 and Wymbs, 2000)). One of the main factors for this growth has been the development of tradeable services (Miles, 2001; Bilderbeek et al, 1998). They seem to represent a high value knowledge-based sector that possesses the vital and active ingredients necessary to shape positive economic change. It can be argued that firms in this sector seem to have, among other things, longterm growth prospects; employment potential and ability to cluster where the rewards from technology transfer and spill over effects are highest. For example McGuire (2002) suggests that the most dynamic trade 
routes of the 21 st century will be dominated by transactions in intangibles rather than goods, where global economic integration and technological (e-business) developments lead to a continual expansion of the range of traded services. Thus the importance of tradeable services to economic growth is likely to increase significantly with rapid development of the service economy and the rise of e-business

Historically in most advanced economies a large proportion of service firms have been small enterprises. Such firms are playing an increasingly important role in high value and sustainable innovative economic growth. Internationally it is estimated that approximately 80 per cent of economic growth can be ascribed to the business activity of SMEs (Jutla et al, 2002). Exploitation of marketing competencies directly linked to ICT is often seen as central to their survival and growth (Durkin and McGowan, 2001). It is speculated that by using such technologies SMEs will be able to capture global markets, sell to international customers and compete favourably with large corporations. However, such speculation seems to ignore two important factors. Firstly firms are heterogeneous in their capabilities, resources and past experiences (Wernerfelt, 1984) and (Barney, 1991) and secondly that there is clear evidence (see for example Srinivasan et al, 2002; Martin and Matlay, 2003 and Raymond 2001) of differences in innovation propensity and style across different service sectors and regional economies.

Recent research (for example Fillis et.al. 2004) has shown that despite technology being a facilitator for improved business practice in terms of developing electronic markets and e-business, SMEs are generally not capitalising on this new mode of conducting business. Many public sector studies suggest that the slow uptake of e-business methods among SMEs is closely associated with internal influences such as managerial attitudes, resources, time pressures, and lack of marketing and information technology skills (see Go Digital Report 2002; DTI Benchmarking report, 2003). Such a view is supported by many academic studies that go on to suggest a central role for governments in promoting the use of ICT in SMEs (Brown, 2002; Martin and Matlay, 2001; Taylor and Murphy 2004) They argue that governments generally do not understand the propensity of SMEs to adopt, assimilate and develop their use of e-business to enhance the way they operate. Relying entirely on output measures of policy impacts means that issues such as how owner-managers perceive technological change, the need for change and the appropriateness of incentives governments are providing to support and achieve it are missed, or only at best slightly understood. Similar results have been found in evaluation studies for the European Union (EU, 2005a and EU, 2005b). It is this gap in understanding SMEs perceptions of government support for e-business that provided the impetus for this study behind this paper. In the next section the methodology adopted by the study is outlined and this is followed by a brief presentation of the results obtained both by using the mixed methodology and in particular the projective techniques. The paper then considers whether these techniques are a useful tool in SME policy evaluation.

\section{METHODOLOGY}

For the study a convenience sample of SMEs (using the European Commission, 1996 definition) in, what could be classified as, knowledge intensive business services (KIBS) was drawn. The firms were located in Northern Ireland, Republic of Ireland and New Zealand. These countries were chosen because they possessed similar characteristics (culture, peripheral location, high dependence on small organisations). In addition research suggested that despite their respective governments' e-business support initiatives, there was a significant technological lag among SMEs in terms of the 'level' of e-business activities (Gray et al, 2003; O’Toole, 2003; Clarke et al, 2003).

To provide a background to the qualitative study a questionnaire was developed from extant literature, and piloted on a small group of academics and business people in Northern Ireland. A total of 1,300 questionnaires were mailed to a cross- section of owner-managers KIBS in the three countries: 400 in Northern Ireland, 400 in the Republic of Ireland and 500 in New Zealand. Contact addresses were solicited from industry organisations and commercial data providers. The questionnaire was first operationalised in Northern Ireland followed by the Republic of Ireland, and finally New Zealand. Appropriate countryspecific changes were made for each country. The questionnaire consisted of both simple factual questions and questions aimed at obtaining views about issues. For the latter a five-point scale with 1 being strongly disagree to 5 being strongly agree was used. 
For the qualitative analysis semi-structured interviews and the projective techniques of word association and completion techniques were used. Semi-structured interviews were conducted with 46 SMEs selfselected from the survey responses. Following on from this a self sample of 10 respondents from each country were selected for further analysis using projective techniques. Word association and completion techniques were chosen as the most useful and feasible projective 'tests' to employ. Word association required owner-managers to read a list of words and then choose those they most associated with the topic. The word association tests included both positive and negative associations relative to perceptions of current e-business support and included words such as generalised, irrelevant, useful, complicated, patronising, and brilliant, with the option given to respondents to add more appropriate words. The completion technique chosen required the participants to complete visible bubble cartoons. The criteria applied in their construction (completion tests) were that they had to be relevant to key issues that emerged from the quantitative survey and ultimately useful to achieve the objectives of the research. The completion tests were created with the aid of web-based resources (images sourced from http://www.google.co.uk). A speech bubble was filled in to assist in the initiation of a conversation, argument, thoughts, perceptions, feelings and emotions.

As an example, the completion tests contained in figure $1 \mathrm{a}$ and figure $1 \mathrm{~b}$ were utilised to establish how the owner-managers perceive government bodies could be of better support to them in their existing and future e-business developments. The speech bubble of the government representative was completed and the following scenario accompanied the projective test:

SMEs may need support from government bodies to assist them in their uptake and use of Internetbased technologies

Respondents were then asked to consider the illustrations and fill in the bubbles to depict what they thought the person was saying and thinking in response to the government representative.

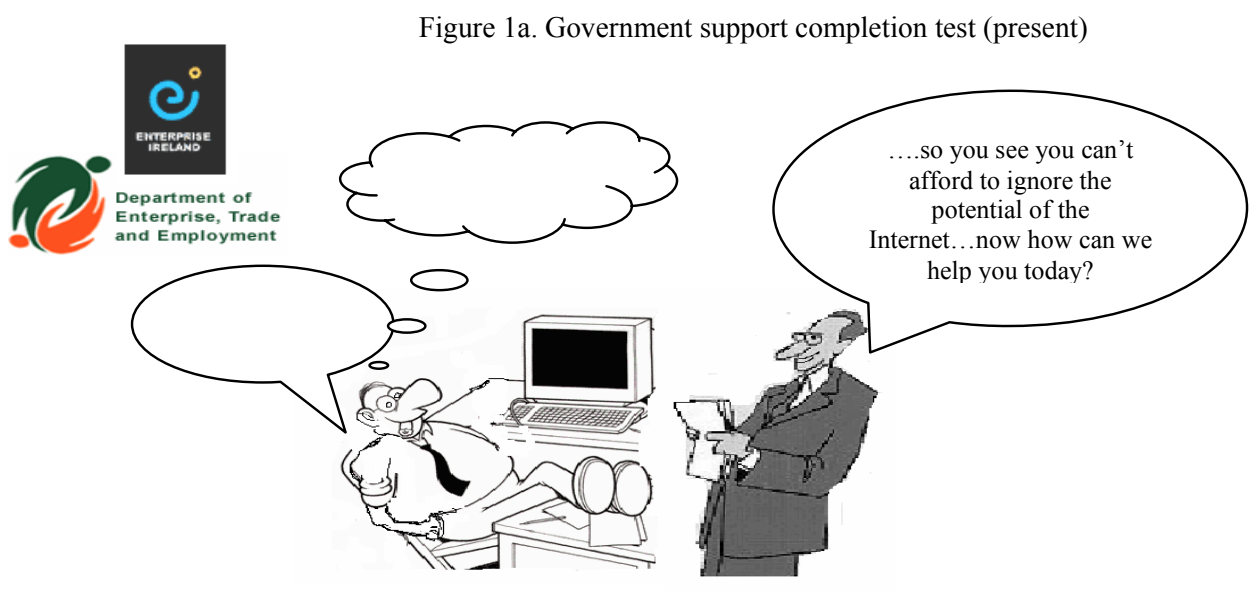

Figure 1b. Government support completion test (future)

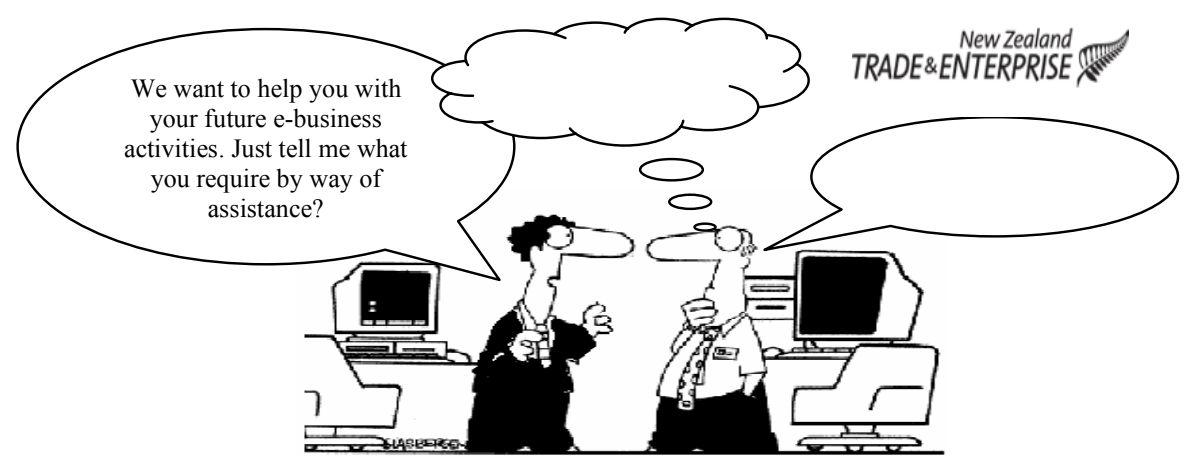


To collate and analyse the results obtained from the use of the completion techniques a quasi-quantitative mapping technique based on qualitative content analysis (Kracauer, 1953), and a modified matrix technique utilised by Swan and Newell (1994) was adopted. Mapping the responses from the projective techniques into useable 'concepts' involved a three stage approach. Firstly content analysis was used as a 'surfacing' technique to search the projective responses for frequency of word usage. From this analysis the 'concepts' were derived. The second stage was 'link description' where concepts that were related were 'linked'. The final stage of the mapping process was property clarification. That is each concept and the relationships that are linked to it were considered and then used to explain the meaning of the concept.

The modified matrix technique was used to uncover cause and effect beliefs that may influence perceptions and behaviour associated with the research problem. The 'half grid' approach was used rather than a 2 X2 approach as it reduced the number of times a relationship needed to be considered, (Swan and Newell, 1994). A causal grid was created in which the variables from the context analysis were listed in the rows and columns. A ' 0 ' was entered if there was no relationship between the row variables and the column variables; $a$ ' 1 ' if the row variable caused a change in the column variable, or $a-1$ if the column variable caused a change in the row variable). The grids for the individual respondents were combined to give a group representation by finding the average for each cell. The main focus of the analysis was the calculation of an 'out-degree' and an 'in-degree' score for each variable in the grid. These scores were obtained by summing the values in the columns and rows, respectively. The out-degree score indicates the number of paths leading from each variable in the grid. The higher the score the more a variable can be seen to cause changes in the other variables. Similarly the in-degree score measures how much a variable is influenced (effect) by other variables and is relative to the number of paths leading to a particular variable from other variables. A higher in-degree score indicates that a variable is seen predominately as an outcome or effect of changes in the other variables. Finally the variables were ranked by both scores. By combining the outcomes of the modified matrix with the qualitative responses achieved from the word association, completion tests and in-depth interviews, the impacts of the related issues associated with government support were further reinforced and clarified.

\section{RESULTS}

The final response rate for the quantitative survey was 30 per cent (393 completed questionnaires). The lowest response was from the Republic of Ireland with only 83 forms returned. The response rate for Northern Ireland (151) and New Zealand (158) were similar. The majority of firms who responded were micro enterprises, (66\%). Within the sample Northern Ireland had the highest percentage of micro enterprises $(74 \%)$ while New Zealand had the lowest percentage (57\%). The average number of employees in the firm was the highest in New Zealand at 19. It also had the most variation in the number of employees with a standard deviation of 29. Northern Ireland firms had the smallest number of employees at 8 and the least variation with a standard deviation of 10 . The corresponding figures for the Republic of Ireland were 11 and 22. Table 1 presents an overall profile of respondents in terms of business sector by region. In-part this can be explained by the inclusion in the response of a number of large legal firms in the New Zealand sample, whereas no legal firms responded in either Northern Ireland or the Republic of Ireland.

In terms of access and usage of ICT the majority of the businesses surveyed $(95 \%)$ had at least one computer and modem to facilitate web-based communication. However, the percentage of firms that had a web site was much lower (64\%). Only $36 \%$ of the web sites have been operational for over 3 years. The level and degree of integration of key information systems with internet-enabled technologies tended to be quite 'primitive'. The main reasons for having a presence on the Internet were: to advertise and promote the organisation's name and intent (60\%); to communicate specific product-service information (54\%); because their competitors had a Web site (49\%); to enhance customer service (44\%); and to communicate with customers and/or suppliers (42\%). Only $4 \%$ maintained a web presence to receive payments.

In all three countries the biggest barrier e-business development was identified as a lack of government support. Statistically there was no significant difference for this barrier between the nations. The survey showed that while the majority of SMEs recognised the importance of employing ICT to develop an ebusiness strategy and a lack of government support was confirmed as the main barrier to e-business 
developments, few were prepared to seek government support. Only five of the original survey sample (two in NI; two in ROI and one in NZ) had sought support from government sources.

The semi-structured interviews failed to elicit much understanding of the responses from the quantitative survey. Most interviewees seemed to have little understanding of the general area of ICT. In a semistructured interview situation there was a lack of response to the prompts given. Also the non-verbals observed gave an impression of them being uncomfortable about discussing the issues. Thus, the project was faced with the general problem of simple mixed methodology research a lack of internally consistency and insight between the two surveys. To address this an emphasis was placed on the projective techniques.

Table 1. Profile of respondents

\begin{tabular}{|c|c|c|c|}
\hline \multirow[b]{2}{*}{ Business Sector } & \multicolumn{3}{|c|}{$\%$ of Sample/(n) } \\
\hline & NI & ROI & NZ \\
\hline \multirow[t]{2}{*}{ Management/Business Consulting } & 16.6 & 7.2 & 13.3 \\
\hline & $(25)$ & (6) & (21) \\
\hline \multirow[t]{2}{*}{ Financial Consultant/Services } & 23.8 & 21.7 & 17.1 \\
\hline & $(36)$ & $(18)$ & (27) \\
\hline \multirow[t]{2}{*}{ Architectural/Building Services } & 9.3 & 12.0 & 10.8 \\
\hline & (14) & $(10)$ & (17) \\
\hline \multirow[t]{2}{*}{ Publishing/Printing } & 6.6 & 7.2 & 10.1 \\
\hline & $(10)$ & (6) & (16) \\
\hline \multirow[t]{2}{*}{ Telecommunications } & 1.3 & 4.8 & 0.6 \\
\hline & (2) & (4) & (1) \\
\hline \multirow[t]{2}{*}{ Recruitment/Employment Services } & 7.3 & 18.1 & 3.2 \\
\hline & (11) & $(15)$ & (5) \\
\hline \multirow[t]{2}{*}{ Travel/Tourism } & 4.0 & 6.0 & 1.9 \\
\hline & (6) & (5) & (3) \\
\hline \multirow[t]{2}{*}{ Marketing/Advertising } & 7.3 & 4.8 & 2.5 \\
\hline & (11) & (4) & (4) \\
\hline \multirow{2}{*}{ Estate Agent/Property Transfer } & 3.3 & 4.8 & 3.2 \\
\hline & $(5)$ & (4) & (5) \\
\hline \multirow{2}{*}{ Education/Training } & 0.7 & 1.2 & 0.0 \\
\hline & (1) & (1) & $(0)$ \\
\hline \multirow[t]{2}{*}{ Engineer Design/Consultant } & 4.6 & 1.2 & 1.3 \\
\hline & (7) & (1) & (2) \\
\hline \multirow{2}{*}{ Computer Services/Software Development } & 9.9 & 10.8 & 6.3 \\
\hline & $(15)$ & (9) & $(10)$ \\
\hline \multirow[t]{2}{*}{ Research/Development } & 0.7 & 0.0 & 0.6 \\
\hline & (1) & $(0)$ & (1) \\
\hline \multirow[t]{2}{*}{ Legal } & 0.0 & 0.0 & 23.4 \\
\hline & $(0)$ & $(0)$ & (37) \\
\hline \multirow[t]{2}{*}{ Other } & 4.6 & 0.0 & 5.7 \\
\hline & $(7)$ & $(0)$ & (9) \\
\hline
\end{tabular}

The main result of the word association tests was that $82 \%$ of the respondents associated negative words with the level of help and support provided by governments. The most used associations were 'generalised', 'simplistic', and 'patronising'. Respondents added 'Other' more appropriate words, with two recurrent associations being made. That is the perception that the extent of government help and support is 'nonexistent' or respondents would raise the questions that generally asked 'what bloody support?'

Tables 2 give the results of the context analysis. Eight variables were identified from the analysis. These variables where used as the basis for the matrix analysis the results of which are given in Table 3. This analysis supported the quantitative analysis. The variable 'government support' has the lowest ranking outdegree score of 2.57, which suggested that it is the least likely to cause change in the e-business decisions of owner-managers. The table can be interpreted as showing that while 'technical skills' ability is perceived by a majority of the respondents as being caused by the propensity to seek 'government support' $(0.70)$; the 'uncertainty' (perception of risk) associated with e-business causes an increase in the propensity to seek 'government support' (0.73); and appropriate 'resources' (financial) fundamentally cause 'technical skills' 
ability to increase (0.83), these factors have not, in practice, caused the majority of these SMEs to seek government support. The negative relationship between government support and resources (-0.40) suggests that funding for e-business from government sources does not cause SMEs to seek it.

Table 2. Descriptors of repertory cause and effect grid variables

\begin{tabular}{|l|l|}
\hline \multicolumn{1}{|c|}{ Grid Variable } & \multicolumn{1}{c|}{ Description } \\
\hline $\begin{array}{l}\text { Innovation } \\
\text { Commitment }\end{array}$ & $\begin{array}{l}\text { Level of innovation propensity } \\
\text { Owner-managers commitment to Internet-based technologies } \\
\text { Resources }\end{array}$ \\
Fovernment & Propensity to seek government support (finances, training initiatives) \\
Technical & Level of technical competences in the firm \\
Product & New product development opportunities \\
Competition & Attitudes towards the threat of competition in the e-business environment \\
Uncertainty & Perception of risk relative to the business/e-business environment \\
\hline
\end{tabular}

Table 3. Causal relationships as perceived by the sample and indegree and outdegree scores

\begin{tabular}{|c|c|c|c|c|c|c|c|c|c|c|}
\hline & 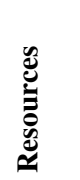 & & 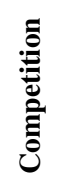 & 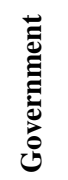 & 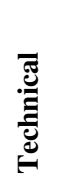 & 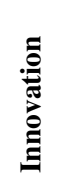 & 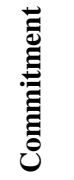 & 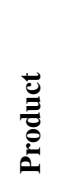 & 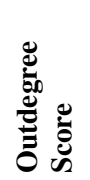 & RANK \\
\hline Government & -0.40 & 0.63 & 0.52 & 0.00 & 0.70 & 0.40 & 0.12 & 0.60 & 2.57 & 8 \\
\hline Innovation & 0.35 & -0.40 & 0.58 & 0.60 & 0.3 & 0.00 & 0.75 & 0.73 & 2.91 & 7 \\
\hline Technical & 0.50 & 0.63 & 0.58 & 0.45 & 0.00 & 0.20 & 0.64 & 0.36 & 3.08 & 6 \\
\hline Product & 0.85 & 0.70 & -0.20 & 0.60 & 0.45 & 0.50 & 0.33 & 0.00 & 3.23 & 5 \\
\hline Commitment & -0.45 & 0.80 & 0.28 & 0.35 & 0.16 & 0.80 & 0.00 & 0.73 & 3.25 & 4 \\
\hline Competition & 0.74 & 0.25 & 0.00 & 0.20 & 0.60 & 0.54 & 0.50 & 0.90 & 3.73 & 3 \\
\hline Resources & 0.00 & 0.50 & 0.70 & 0.44 & 0.83 & 0.30 & 0.63 & 0.46 & 3.86 & 2 \\
\hline Uncertainty & 0.60 & 0.00 & 0.30 & 0.73 & 0.60 & 0.93 & 0.72 & 0.13 & 4.41 & 1 \\
\hline Indegree Score & 2.19 & 2.83 & 3.16 & 3.27 & 3.64 & 3.67 & 3.69 & 3.91 & & \\
\hline RANK & 8 & 7 & 6 & 5 & 4 & 3 & 2 & 1 & & \\
\hline
\end{tabular}

The context and mapping analysis are an attempt to provide a quasi-quantitative analysis of the qualitative data derived from the projective techniques. While they provide a good summary of the results they hide something of the Pandora's Box of attitudes and perceptions that the techniques uncover. Reporting such 
qualitative results succinctly is difficult. The annex to the paper provides an extremely simplified analysis of some of the responses obtained from the projective techniques.

\section{THE USEFULNESS OF PROJECTIVE TECHNIQUES}

The results of the quantitative analysis supports the contention of Bennett and Robson (1998); Storey (1994); Kai-Uwe Brock (2000) and Fallon and Moran, (2000) by only providing a limited understanding of the contextual issues and circumstances which may affect firms. In all three countries it highlighted the lack of government support as being the main barrier to e-business development but failed to address the issue of why this should be the case. Adopting a traditional qualitative approach using semi-structured interviews proved, as discussed by Hoskin (2002), to be insufficient to obtain much insight into the issues raised by the quantitative study. In the face-to-face interview situation respondents' constrained their discussion of the issues and seemed to provide answers that were of a 'politically correct' nature because they were what they expected the interviewer to want.

The word association test gave a simple way for the owner-managers to consider their perceptions of their respective governments' current supporting roles in providing them with information and practical help about how to develop an e-business. The responses from the projective techniques seemed to provide much deeper cognate thoughts (e.g. pre-conscious, conscious, intuitive, associative) relative to the concepts of interest. The way the interviewees interpreted the cartoons revealed much about their own emotions, feelings and perceptions. The visuals helped to focus the owner-managers on the 'heart' of the subject: their perceptions. This served to minimize the 'politically correct' discourse that interviewees tend to produce.

The ability of the context and matrix analysis to extract the concepts closely related to owner-managers' perceptions is central to the validity of the approach. The findings of this analysis are supported by the triangulation of the results with the word association tests and the quantitative survey. Thus the use of these instruments can be justified. Importantly the projective techniques had the ability to get beyond the rational replies respondents made in an interview situation (Hoskin, 2002; Branthwaite, 2002).

The projective techniques made little or no demand in terms of literacy or academic skills on the part of the interviewee. They were predominantly visual, largely independent of particular languages, and in some cases did not involve speech at all. Their scope was therefore much wider than that of self-reporting or rating procedures (Thorndike in Berkman \& Gilson, 1986). However, a major disadvantage of projective techniques is the complexity of the data and the corresponding skills required of the researcher (Burns \& Lennon, 1993). Even with the use of techniques such as context and matrix analysis the responses are not easily codified and need careful evaluation by researchers who are both trained and skilled interpreters of information. A considerable degree of subjectivity applies in the interpretation of responses to projective techniques, and researchers frequently disagree among themselves (Sampson, 1987 and Churchill, 1991). The need for highly skilled research staff mean that projective techniques are expensive to administer.

There are other standard criticisms of projective techniques. The results of projective techniques can not normally be generalised as they are not derived from statistically significant samples (Webb, 1992). It may be difficult to get the subjects to project themselves into the roles the researchers wish them to assume. Some subjects may not agree to participate in exercises such as role playing (Webb, 1992 and Berkman \& Gilson, 1986). Finally the reliability of measures is very difficult to establish. However, triangulation can help to ensure reliability (Belk et al in Burns \& Lennon, 1993).

Despite these challenges the ability of projective techniques to go beyond standard inflexible measurement procedures seems ideally suited to the complex environment of SMEs. It has been argued that decision making in SMEs is different from larger firms (Martin and Matlay 2003; Blili and Raymond, 1993). Projective techniques appear to be able to address both the widely varying decision processes and individuality of SMEs (Zheng et al, 2004). Thus the use of these techniques could provide some of the tools toward a fuller understanding of the way entrepreneurs and small firms identify and develop business opportunities. The need for such tools was argued for by Taylor and Murphy (2004). 


\section{CONCLUSION}

Policy evaluation is a complex issue and while most approaches now use a mixed methodology there is a general acceptance more consideration needs to be given into how perceptions and attitudes can be measured. In this paper the applicability of projective techniques, an approach widely used in psychology and consumer studies to elicit more cognate thoughts than could be obtained by asking direct questions, has been considered. To test the applicability of the projective techniques they were used in a study of responses from owner-managers of SMEs in the tradeable services sector to government policy on e-business. The study involved SMEs from Northern Ireland, Republic of Ireland and New Zealand. Because the small business community undergoes a continuous process of revising and reconstructing experiences in order to combat the mitigating circumstances created by the dynamic nature of their immediate business environment, (Bygrave, 1989; Schumpeter, 1942) they provided an ideal testing ground for the use of the projective techniques. Their use was also justified on the basis that the traditional quantitative and qualitative approaches failed to elicit conclusive results. While the study only considered two projective techniques, word associations and completion, the usefulness was demonstrated. By analysing the results using quasi-quantitative interpretation methods such as context and matrix analysis, summaries of the extensive qualitative findings were possible. Overall the mixed method approach of the study facilitated a deeper understanding of how owner-managers perceived current government support for e-business. The paper also illustrates that by using an extended mixed methods approach, incorporating projective techniques, evaluators can consider more fully, the heterogeneous perceptions of small and medium service sector enterprises. Thus it would appear that the research approach could provide policy makers with a more 'accurate' basis upon which to base public policy formation and support mechanisms for e-business.

While the conclusions of this paper are positive about the role of projective techniques in policy evaluation there are still many issues to be addressed. Projective techniques are expensive to use and normally not generalisable. Also the study only used two possible methods and these and other possible methods need to be assessed in other policy areas and countries. Despite these issues it would appear that projective techniques have a role to play in the development of policy evaluation methods.

\section{REFERENCES}

Barker, A., et al, 2001, 'Informed eclecticism: a research paradigm for the $21^{\text {st }}$ Century', International Journal of Marketing Research, Vol.43, No.1, pp3-27

Barney, J.B., 1991, 'Firm resources and sustained competitive advantage', Journal of Management, Vol.17, (March), pp. $99-120$

Bayoumi, T.and Haacker, M., 2002, 'It's Not What You Make, It's How You Use IT: Measuring the Welfare Benefits of the IT Revolution Across Countries,' CEPR Discussion Papers 3555, C.E.P.R. Discussion Papers.

Berkman, H.W.and Gilson, C. 1986, Consumer behaviour, concepts and strategies. 3rd ed. Boston. Kent.

Bellak, L. 1992, Projective techniques in the computer age, Journal of Personality Assessment, Vol.58, pp.445-453.

Burns, L.D. and Lennon, S.J., 1993. Social perception: methods for measuring our perception of others. International Textile and Apparel Association Special Publication, Vol. 5, pp. 153-159.

Bennett, R., and Robson, P., 1998, 'External advice and business links', in A. Cosh and A. Hughes (Ed.) Enterprise Britain, Growth, Innovation and Public Policy in the Small and Medium Sized Enterprise Sector 1994-1997, ESRC Centre for Business Research, Cambridge. 1998

Bilderbeek, R., et al, 1998, 'Services in innovation: knowledge intensive business services (KIBS) as co-producers of innovation', S14S Synthesis Paper, [online] available at URL: http://les.man.ac.uk/PREST/Download/finalrp3.pdf accessed on 20th May, 2003

Blili, S., and Raymond, L., 1993, 'Information Technology: threats and opportunities for small and medium-sized enterprises', Journal of Information Management, Vol.13, pp.439-448

Branthwaite, A., 2002, 'Investigating the power of imagery in marketing communication: evidence-based techniques', Qualitative Market Research: An International Journal, Vol.5, No.3, pp. 164-171

Brown, E., 2002, 'Accelerating the uptake of e-commerce by small and medium enterprises', [online] available at URL: http://www.setel.com.au/smeforum2002/final report accessed on 3rd January 2003

Burns, L.D., and Lennon, S.J., 1993, 'Social perception: methods for measuring our perception of others', International Textile and Apparel Association Special Publication, Vol.5, pp. $153-159$ 
Bygrave, W. D., 1989, 'The Entrepreneurship Paradigm (I): A Philosophical Look at its Research Methodologies',

Entrepreneurship Theory and Practice, Vol.14, No.1, pp. 7-26.

Churchill, G.A., 1991, Marketing research methodological foundations $\left(5^{\text {th }}\right.$ Ed.) Chicago: Dryden Press

Clarke, D., Bowden, S., and Corner, P., 2003, 'E-business in New Zealand 2000-2002: are we ready for the digital economy?' University of Auckland Business Review, Vol.5, No. 2, pp. 79-90.

Creswell, J.W., 2003, Research Design: Qualitative, Quantitative and Mixed Methods Approaches. (2 ${ }^{\text {nd }}$ Ed), Thousand Oaks, California: Sage

Department of Trade and Industry, 2003, 'Business in the Information Age: The International Benchmarking Study', [online] available at URL: http://www.ukonlineforbusiness.gov.uk/bechmarking2003/index.htm accessed on 20th January 2004

Durkin, M., and McGowan. P., 2001, 'Net effect-views from the periphery: exploring the role and importance of the Internet on marketing activity in entrepreneurial firms', Irish Marketing Review, Vol. 14, pp.15-25

Edwards, W., 1954, 'The theory of decision-making', Psychological Bulletin, Vol. 51, pp. 380-417

EU, 2005a, Impact Assessment of Regional \& National E-Business Policies: Impact Assessment Report 1 European Commission, Enterprise Directorate General, e-Business, ICT Industries and Services

EU, 2005b, Impact Assessment of Regional \& National E-Business Policies: Final Impact Assessment Report European Commission, Enterprise Directorate General, e-Business, ICT Industries and Services

Information Society Benchmarking Report, 2005, [online] available at URL:

http://europa.eu.int/information_society/eeurope/i2010/docs/benchmarking/051222\%20Final\%20Benchmarking\%20Rep ort.pdf

Fallon, M., and Moran, P., 2000, 'Information communication technology (ICT) and manufacturing SMEs', paper presented at The 2000 Small Business and Enterprise Conference. Manchester University, Manchester, pp.100-109

Fillis. I., et al, 2004, 'Factors impacting on e-business adoption and development in the smaller firm'. International Journal of Entrepreneurial Behaviour and Research, Vol.10, No.3, pp178 -191.

Go Digital, 2002, Progress Report, [online] available at URL: http://europa.eu.int/comm/enterprise/ict/policy/doc/sec_2002_566.pdf accessed on 17th May 2003

Gordon, W., and Langmaid, R., 1988, Qualitative market research. Gower: Aldershot

Graham, J.R., and Lilly, R.S., 1984, Psychological testing, Prentice-Hall, Englewood Cliffs, New Jersey

Gray, B., et al, 2003, 'Overcoming barriers to better performance in Service Businesses'. Marketing Performance Centre: University of Otago.

Hauknes, J., 1996, 'Innovation in the service economy', STEP Report available online at: URL: http://www.step.no/reports/y1996/0796.pdf accessed on 20th February 2006

Hoskin, F., 2002, 'How do we ask questions and how do we know what it all means?' [online] available at URL: http://www.nop.co.uk/news/PDE/BIG_Conference.PDF accessed on $9^{\text {th }}$ September 2002

ISI, 1999, ISI Mission Statement, (Information Society Initiatives), [online] available at URL: http://www.ukonline.gov.org accessed on $14^{\text {th }}$ June 2002

Jutla, D., et al, 2002, 'Supporting the e-business readiness of Small and Medium-sized Enterprises: Approaches and Metrics'. Internet Research: Electronic Networking Applications and Policy, Vol.12, No.2, pp. 139-164.

Kai-Uwe Brock, J., 2000, 'Information and technology in the small firm' in S.Carter and D. Jones-Evans (Eds.), Enterprise and Small Business: Principles, Practice and Policy. Financial Times: Prentice-Hall.

Kassarjian, H.H., 1974, 'Projective methods', in R. Ferber (Ed.), Handbook of Marketing Research. New York: McGrawHill

Kracauer, S., 1953, 'The challenge to qualitative content analysis', Public Opinion Quarterly, Vol.16, pp. 631 - 642

Loudon, D.L., and Della Bitta, A.J., 1993, 'Consumer behaviour, concepts and application', (4 ${ }^{\text {th }}$ Ed.) New York:McGraw-Hill

Lowenthal, T, 1999, 'The Future of Federal Statistics in the Information Age - Discussion', Journal of Official Statistics, Vol. 15, No. 3, pp. 367-372.

March, J., and Simon, H., 1958, Organisations, New York: John Wiley and Sons

Martin, L.M., and Matlay, H., 2003, 'Innovative use of the Internet in established small firms: the impact of knowledge management and organisational learning in accessing new opportunities', Qualitative Market Research: An International Journal, Vol. 6, No.1, pp. 18-26

Martin, L.M., and Matlay, H., 2001, "Blanket" approaches to promoting ICT in small firms: some lessons from the DTI ladder adoption model in the UK', Internet Research: Electronic Networking Applications and Policy Vol. 11 No. 5, pp. $399-410$ 
McGuire, G., 2002, 'Market access opportunities and benefits of liberalisation for developing economies', [online] available at URL: http://192.91.247.38/tab/pubs/itcdtab20_en.pdf accessed on $25^{\text {th }}$ September 2003

Miles, I., 2001, 'Services innovation: a reconfiguration of innovation studies', [online] available at URL http://les.man.ac.uk/PREST/Publications/DP_PDFs/PRESTDPO1-05.pdf accessed on 7th August 2002

Nahuis R. and P J.G. Tang, 2004, 'Strategic Policy Competition with Public Infrastructure,' Working Papers 04-24, Utrecht School of Economics.

O'Toole, T., 2003, 'E-relationships - emergence and the small firm', Marketing Intelligence and Planning, Vol.21, No.2, pp. $115-122$

Raymond, L., 2001, 'Determinants of web site implementation in small business, Internet Research: Electronic Networking Applications and Policy, Vol. 11, No.5

Sampson, P., 1987, 'Qualitative research in Europe: the state of the art and the art of the state' in P. Sampson (Ed) Qualitative research: the old the new and a question mark, ESOMAR Marketing Research Monograph, Vol. 2 (Amsterdam)

Schumpeter, J.A., 1942, Capitalism, Socialism and Democracy. New York: Harper and Row

Solomon, M.R., 1994, Consumer behaviour: buying having and being, ( $2^{\text {nd }}$ Ed.). Boston: Allyn and Bacon

Srinivasan, R., et al, 2002 'Technological opportunism and radical technology adoption an application to e-business', [online] available at URL: http://www.msce.external.Xerox.com/isbm/dscgi/ds.py/Get/File-194/1-2002.pdf accessed on $8^{\text {th }}$ August 2002

Storey, D.J., 1994, Understanding the small business sector, London: Routledge

Storey D, 2002, 'Methods of evaluating the impact of public policies to support small businesses: the six steps to heaven', International Journal of Entrepreneurship Education, Vol. 1, pp.181 - 202

Swan, J., and Newell, S., 1994, 'Managers' beliefs about factors affecting the adoption of technological innovation: a study using cognitive maps'. Journal of Managerial Psychology, Vol.9, No.2, pp.3-11

Taylor M, and Murphy, A., 2004, 'SMEs and E-business', Journal of Small Business and Enterprise Development, Vol. 11, No. 3, pp. 280-289.

Wagner, E.E., 1995, 'A logical analysis of projective techniques based on independence of items and latitude of response', Perceptual and Motor Skills Vol. 81, pp. 868-870.

Webb, J.R., 1992, Understanding and designing marketing research. London: Academic Press

Wernerfelt, B., 1984, 'A resource-based view of the firm', Strategic Management Journal, Vol.5, No.2, pp. 171-180

Wymbs, C., 2000, 'How e-commerce is transforming and internationalising service industries', Journal of Services Marketing, Vol.14, No.6, pp.463-477

Zeithaml, V.A., and Bitner, J., 1996, Services Marketing, New York: McGraw-Hill

Zheng, J., et al., 2004, 'Small firms and e-business: cautiousness, contingency and cost-benefit', Journal of Purchasing and Supply Management, Vol.10, pp.27-39

\section{ANNEX}

Projective techniques allow for the researcher to explore further the attitudes and perceptions of the interviewee. It can be compared to opening a Pandora's Box of information. Below are some of the issues raised by interviewees during the process. These hopefully give some idea of the insight that be gained by the technique.

\section{E-business policy formation and information dissemination}

Based on the responses about e-business information dissemination to small firms via government departments, it was evident that very few of the respondents had received that information, or had read any information received. It was stated that 'an e-business information campaign would be useful' (Travel, NI). A financial advisor from ROI commented 'I don't think there is any support for e-business that I am aware of'. Another businessman asserts:

'for local business I don't see any local support... if there is a fund or information available to support an e-business strategy I don't know about it...',

(Recruitment, NZ). 
Indeed despite the fact that

'many SMEs are realising the potential for e-business, there's a lot of confusion about where one should go to get guidance or financial assistance to develop e-business'

(Marketing/Advertising, NI).

\section{SME ‘'’ business funding applications}

Funding application issues concerned the nature of the process viewed by one owner-manager as 'cumbersome, complicated, with no transparency. It (the application process) imposes an awful lot of rules that many businesses would have difficulty complying with to get the grants...unrealistic targets that in many cases could not possibly be met',

Another responds by stating:

(Insurance broker, NI).

'I feel quite bitter. We just gave up half way through the process because of all the bureaucracy and form filling...but I don't regret having no government support and we would always be accountable

(Recruitment Consultant, ROI).

It was also inferred that any future involvement with the government was based on past experience where advice and support for SMEs and public policy developments were viewed as not being sympathetic to the small business owner. A design engineer from ROI retorted:

'until the business, never mind the e-business environment is better sorted, I personally think the government should butt out rather than trying to be more involved.

The general belief was that

'there are already plenty of government barriers to conducting business efficiently, most notably 'the high levels of compliance costs',

(Financial services, NZ).

\section{Lack of trust in the judgment of government bodies}

There was also a general lack of trust in the judgment of government bodies in relation to what constitutes a viable business/e-business venture. This perspective is also based on past involvement with and experience of, decisions made by these government agencies to support new and innovative ideas. Comments such as:

'Governments are notorious for not spotting winners and often backing losers. Yes governments create the landscapes, but good ideas will always find the cash...we will never seek government funding even though it (government support) is generally lacking'

(Recruitment, NZ).

Or 'if the prerequisites for financial support from the government could be achieved, then most likely either we would no longer need funding or we could raise it ourselves',

(Legal services, NZ).

This led to quite a high level of resentment, borne out by the comments of a software developer in NI who scowled

'if small firms were depending on INVESTNI they would not get very far in their business or $e$ business developments!'

Some SMEs accused e-business policies of being 'far too woolly and not sectorally focused enough' (Financial consultant, ROI) and the perception that they (e-business policies) 'have not come down to the right level yet to be of value to the small business community (R\&D, NZ).

\section{Entrepreneurial bravado}

'Entrepreneurial bravado' impinged on attitudes associated with the suggestion of government support. The main finding relative to this was that many believed they (SMEs) 'would not need, nor want governments dictating their future business and e-business development strategies' (Legal, NZ). A respondent from the architectural services in ROI stated:

'I resent the government thing and senior politicians saying industry has to be dragged into the $21^{\text {st }}$ century and e-business. They don't. Industry will bloody well innovate and they will do things that 
make sense. No-one 10 years ago...even yet...said give up your old drawing boards and create a paperless e-business environment...we just did it because it made good business sense".

Additionally the independence to run the business according to their own agenda and stand on their "own feet' financially was seen as more preferable than seeking financial help and support from government bodies. This assertion was reinforced by respondents who thought:

'E-business is a commercial decision so I don't see any relevance to government input. After all you don't look to the government to pay your phone bill',

(Financial consultant, NZ).

'Government support of any kind doesn't enthral me at all. If I want to do something I want to do it my way...I want to do it without some bloody government official looking over my shoulder saying you must fill out these forms before this can happen and that can happen!'

(Architect, ROI)

Thus many owner-managers remained unconvinced, dismissive and resentful of the suggestion of support from government bodies. A Real Estate agent's (NZ) response is typical of projected thoughts in this respect: 'Pen-pushing upstarts - they (government bodies) have no idea what my business needs are. Nor am I going to tell them...we will survive without their support!'

(Real estate, NZ) 